\title{
LA LIMITACIÓN CONSTITUCIONALA LA REELECCIÓN DE AUTORIDADES EJECUTIVAS, SU CONVENCIONALIDAD Y LEGITIMIDAD \\ POPULAR: UNA CRÍTICA A LA SENTENCIA DEL TRIBUNAL CONSTITUCIONAL PLURINACIONAL BOLIVIANO
}

Luis Gonzalo Inarra Zeballos(a)

CONSTITUTIONAL LIMITATION TO THE RE-ELECTION OF EXECUTIVE AUTHORITIES, THEIR CONVENTIONALITY AND POPULAR LEGITIMACY: A CRITICISM TO THE SENTENCE BY THE PLURINATIONAL CONSTITUTIONAL COURT OF BOLIVIA

A LIMITAÇÃO CONSTITUCIONAL À REELEIÇÃO DE AUTORIDADES EXECUTIVAS, SUA CONVENCIONALIDADE E LEGITIMIDADE POPULAR: UMA CRÍTICA À SENTENÇA DO TRIBUNAL CONSTITUCIONAL PLURINACIONAL DA BOLÍVIA

Fecha de recepción: 7 de agosto del 2018

Fecha de aprobación: 7 de febrero del 2019

Disponible en línea: 1 de marzo del 2019

Sugerencia de citación:

Inarra Zeballos, L. I. (2019). La limitación constitucional a la reelección de autoridades ejecutivas, su convencionalidad y legitimidad popular: una crítica a la sentencia del Tribunal Constitucional Plurinacional boliviano. Razón Crítica, 6, 237-255, doi: 10.21789/25007807.1454

(a) Luis Gonzalo Inarra Zeballos

Abogado del IDEI

Profesor titular en las materias Derecho Internacional y Filosofía del Derecho, y Derechos

Humanos de la Universidad Mayor de San Simón, Bolivia

Vicepresidente del Instituto de Estudios Internacionales de Bolivia

https://orcid.org/0000-0001-9470-4401

luinarra@gmail.com 


\section{R E S U M E N}

El presente artículo tiene el objetivo de mostrar que una adecuada interpretación de la Convención Americana sobre Derechos Humanos o Pacto de San José por parte del Tribunal Constitucional Plurinacional de Bolivia, en el caso sobre la reelección de autoridades nacionales y subnacionales, no solo habría consistido en la aplicación correcta del Control de Convencionalidad, sino lo que es más relevante aún, hubiese hecho plenamente compatible su sentencia con la decisión popular expresada en el referéndum del 21 de febrero del 2016, cuyo resultado fue el rechazo a la propuesta de modificación a la Constitución boliviana para incluir una segunda reelección del presidente y vicepresidente. Una decisión así no habría ocasionado una paradoja entre voluntad popular (democracia) y convencionalidad (derecho internacional de los derechos humanos) respecto al caso en cuestión.

PALABRAS CLAVE: derecho a ser elegido, referendo del 21 de febrero del 2016, límites a los derechos, reelección, interpretación, argumentación, control de convencionalidad. 


\section{A B S T R A C T}

This article intends to show that an adequate interpretation of the American Convention on Human Rights, also known as the Pact of San José, by the Plurinational Constitutional Court of Bolivia on the re-election of national and subnational authorities, not only would implied the correct application of the Control of Conventionality, but also the creation of a fully compatible sentence with the popular decision expressed in the referendum of February 21, 2016, whose result was to reject the proposed amendment to the Bolivian Constitution in order to include a second re-election of the president and the vice president. Such a decision would have never caused a paradox between popular will (democracy) and conventionality (international human rights law) regarding this particular case.

KEY WORDS: Right to be elected, popular will of February 21, 2016, limits on rights, re-election, interpretation, argumentation, conventionality control.

\section{R E S U M O}

Este artigo tem como objetivo mostrar que se o Tribunal Constitucional Plurinacional da Bolívia tivesse feito uma interpretação correta da Convenção Americana sobre Direitos Humanos, também conhecida como Pacto de San José da Costa Rica, no caso da reeleição de governos nacionais e subnacionais não só teria consistido na aplicação correta do controle de convencionalidade, senão, no que é mais relevante ainda, teria tornado sua sentença totalmente compatível com a decisão popular expressa no referendo de 21 de fevereiro de 2016, que resultou na rejeição da proposta de emenda à Constituição boliviana para incluir uma segunda reeleição do presidente $\mathrm{e}$ vice-presidente. Tal decisão não teria causado um paradoxo entre a vontade popular (democracia) e convencionalidade (direito internacional dos direitos humanos) sobre o caso em questão.

PALAVRAS-CHAVE: direito de ser eleito, vontade popular de 21 de fevereiro de 2016, limites dos direitos, reeleição, interpretação, argumentação, controle de convencionalidade. 


\section{Introducción y delimitación temática}

Es hoy conocida, incluso en el contexto internacional, la situación política en la que se encuentra Bolivia, ya que después que el Tribunal Constitucional Plurinacional (тСP) dictara la Sentencia 84 del 2017, cuyos efectos constituyeron una habilitación para la repostulación y consecuente reelección del presidente y vicepresidente, se ha producido una evidente contrariedad con los resultados del referendo del 21 de febrero del 2016 $\left(21 \mathrm{~F}^{1}\right)$, en el que la mayoría del pueblo boliviano rechazó la modificación del artículo 168 de la Constitución con el fin de impedir una nueva repostulación de las mencionadas autoridades.

El mecanismo mediante el cual el TCP ha fundado su decisión ha sido la aplicación del control de convencionalidad, lo que hace que pueda pensarse que la normativa convencional o internacional y la consecuente interpretación del Pacto de San José sean contrarios a la voluntad soberana del pueblo boliviano, expresada en la consulta popular señalada anteriormente, y peor aún que en el presente caso pueda existir una paradoja entre la construcción democrática de los derechos y sus límites y el derecho internacional de los derechos humanos.

Estas contradicciones son aparentes y pueden refutarse por medio de una interpretación más coherente y compacta del Pacto de San José sobre el derecho a ser elegido democráticamente en relación con los límites de su ejercicio, en especial respecto a la prohibición de más de una reelección contenida en diversas disposiciones constitucionales y legales del Estado boliviano. En otras palabras, se pretende demostrar que el referido límite de una sola reelección no es contrario a normas convencionales, y que

$121 \mathrm{~F}$ es la expresión popular que hace referencia a la decisión del referendo del 21 de febrero del 2016. 
precisamente estas son plenamente coherentes con la voluntad popular que reafirmó aquella limitante en el 2016.

Para demostrarlo, se hará referencia a las condiciones normativas (legalidad) con las que el caso en cuestión ha sido resuelto por el TCP, es decir, aquellas normas constitucionales y convencionales que han entrado en juego para la adopción de la Sentencia 84 del 2017; después, se analizarán algunos criterios de racionalidad interpretativa-argumentativa que el tribunal debió considerar para hacer más consistente y legítima su decisión. Por último, veremos que la sentencia constitucional obvió ciertas normas convencionales y criterios interpretativos de la Corte Interamericana de Derechos Humanos que hubiesen permitido justificar el límite de una sola reelección para autoridades nacionales y subnacionales.

\section{La Sentencia 84 del 2017 y la paradoja entre democracia y convencionalidad}

El TCP, en la referida Sentencia 84 del 2017 del 28 de noviembre de ese año, resolvió:

De acuerdo a lo dispuesto por el art. 256 de la Norma Suprema la APLICACIÓN PREFERENTE del art. 23 de la Convención Americana sobre Derechos Humanos, por ser la norma más favorable en relación a los Derechos Políticos, sobre los arts. 156, 168, 285.II y 288 de la Constitución Política del Estado, en las frases 'de manera continua por una sola vez' de los arts. 156 y 168 y 'de manera continua por una sola vez' de los arts. 285.II y $288[\ldots]$.

El TCP declaró además la inconstitucionalidad de los correlativos artículos de la Ley del Régimen Electoral, los cuales también establecen una sola reelección de autoridades nacionales y subnacionales (TCP, 2017, SCP 84). Esta decisión la tomó ejerciendo de manera simultánea los controles de constitucionalidad y de convencionalidad. En tal sentido, ante una decisión de tal magnitud, sin precedentes en la historia nacional, cabe preguntarse cuán legítima y legal es.

Como es sabido, los magistrados que componen el TCP se eligen democráticamente por sufragio universal, según lo establece el artículo 198 de la Constitución. Esta situación, bien podría constituirse en un elemento para demostrar la legitimidad suficiente de la que gozaría 
este tribunal, incluso como respuesta a críticas de teóricos como Waldron (2005, pp. 338-351), que arremeten contra el control judicial (o control de constitucionalidad) precisamente por su falta de legitimidad democrática para definir derechos. Sin embargo, si consideramos que el propio pueblo ha resuelto, por mayoría, en el referendo del 21 de febrero del 2016 rechazar una segunda reelección presidencial, se justifica dudar de esta legitimidad para el caso en concreto (oEP, 2011) ${ }^{2}$. De esta forma, resta indagar en la cuestión de cuán legítimo y racional fue el discurso interpretativo y argumentativo que ha desarrollado el TCP para justificar su decisión.

En la sentencia se observa que el tribunal, en función al artículo 256 de la Constitución, ha establecido que los derechos políticos contenidos en el artículo 23 de la Convención Amerciana sobre Derechos Humanos (CADH) son más amplios y favorables que los contenidos en la Constitución, los cuales no tendrían ningún tipo de limitaciones o restricciones, sino únicamente en los casos establecidos en el numeral 2 del mencionado artículo 23 (llamados numerus clausus, compuestos por la edad, la nacionalidad, la residencia, la instrucción, la capacidad civil o mental y la condena por juez competente en proceso penal). En consecuencia, al no estar previsto explícitamente el impedimento o limitación a la reelección de autoridades nacionales y subnacionales en los denominados numerus clausus, las normas constitucionales y de la ley electoral estarían restringiendo de manera inconvencional el derecho de estas autoridades a ser elegidas en elecciones periódicas, como señala el artículo 23.2 de la CADH (TCP, 2017, SCP 84).

Este panorama conlleva ineludiblemente a que se presente una paradoja entre la decisión popular (democrática) que impide una segunda reelección de autoridades y la convencionalidad de los derechos humanos, que, según el TCP, niega dicho límite, lo que permite la repostulación indefinida a cargos ejecutivos electos, como el de presidente y vicepresidente. Es decir, estaríamos ante una colisión irremediable entre legitimidad democrática y legalidad convencional o internacional. Ahora bien, creemos que esta dicotomía es aparente y que es posible desentrañarla con la aplicación correcta de normas constitucionales y convencionales (una dimensión normativa), y con una adecuada interpretación y argumentación discursiva del caso (una dimensión discursiva). 


\section{La dimensión normativa aplicable al caso}

En el marco de la dimensión normativa aplicable al caso previamente es necesario identificar en la estructura normativa del Estado constitucional y convencional de Derecho sus elementos o mecanismos que lo caracterizan: 1) un procedimiento de reforma constitucional más complejo que el de reforma legal, 2) un mecanismo de control de constitucionalidad y 3), sumándose a estos, un elemento que es propio del aspecto convencional, el control de la convencionalidad (Gil, 2014, p. 161). La reforma constitucional y el control de constitucionalidad son bastante conocidos en la literatura constitucional; no obstante, es importante recordar que en el contexto boliviano de la reelección todos estos mecanismos ya han sido ejercidos por las instancias de autoridad constitucionalmente establecidas, cuyos resultados son recíprocamente contradictorios. Esto produce un conflicto de autoridad evidente.

Ahora bien, el Estado boliviano, en palabras de Andrés Gil Domínguez, es un ejemplo de lo que él denomina Estado constitucional y convencional de derecho (2014, pp. 29-42), debido a que, además de contener un extenso catálogo de derechos fundamentales, la Constitución del 2009, como ninguna otra que Bolivia haya tenido, ha incorporado normas de reconocimiento del derecho internacional, especialmente, del derecho internacional de los derechos humanos.

En primer lugar, es un Estado constitucional por la presencia normativa de la acción de inconstitucionalidad establecida por los artículos 132, 133, 196 y ss. de la Constitución, y está dotada de un procedimiento de reforma constitucional incorporado en el artículo 411; como vimos, en relación con la reelección, ambos mecanismos ya han sido empleados. En segundo lugar, es un Estado convencional, porque además de incluir todo un capítulo referido a las normas sobre relaciones internacionales (arts. 255-268), la Constitución de Bolivia, en el artículo 410. II, relativo a la jerarquía normativa, ha incorporado dentro del "bloque de constitucionalidad" tratados e instrumentos internacionales sobre derechos humanos, al igual que normas sobre derecho comunitario. Esta disposición es la que atribuye a las normas internacionales de derechos humanos una cualidad y jerarquía constitucional, haciendo que la Constitución, en su parte dogmática, se amplíe a tales instrumentos sobre la materia en cuestión. 
Específicamente, en relación con esta materia, la Constitución también ha incluido otros dos postulados normativos que serán útiles para el discernimiento de la temática que nos encontramos tratando, siendo estos los que están incluidos en los artículos 256 y 13.IV, que respectivamente refieren a: 1) la aplicación preferente de normas internacionales de derechos humanos cuando son más favorables para la persona que aquellas contenidas en la Constitución (interpretación pro homine) y 2) la obligación de interpretar las normas de derechos humanos conforme a instrumentos y tratados internacionales sobre la materia (interpretación conforme). Estos postulados, sumados a la jurisprudencia de la Corte Interamericana de Derechos Humanos sobre el Control de Convencionalidad, dan lugar a que este se instaure judicialmente. Como veremos, fueron precisamente estos preceptos normativos e interpretativos los que le permitieron al TCP tratar de justificar su sentencia sobre la cuestión de la reelección, que a continuación pasamos a analizar.

\section{Sobre la legitimidad de la sentencia constitucional 84 del 2017}

Se ha hecho evidente la pugna por quién debe tener la última palabra sobre los derechos, en especial sobre el supuesto derecho de reelección indefinida, pues el referendo fue un mecanismo de reforma constitucional el 21 de febrero del 2016 y permitió rechazar la ampliación del mandato de las autoridades ejecutivas a dos reelecciones consecutivas, y, por otro lado, el TCP decidió la inaplicación de normas constitucionales y legales sobre límites a la reelección al aplicar el control de convencionalidad. En este sentido, debemos observar que los derechos están íntimamente vinculados a la democracia, en la que lo deseable es que los ciudadanos vivan conforme a esta y sean partícipes de la construcción de sus derechos, al recaer en ellos fragmentos de soberanía (Ferrajoli, 2013, p. 43). Sin embargo, ya que son constitucionalizados o internacionalizados, los derechos poseen en su narrativa un contenido muchas veces ambiguo e incluso indeterminado, que, al tratar de aplicarlos a un caso en concreto, pueden generar en el intérprete dudas que le llevarán a tratar de colmarlas de determinada manera. Ahora bien, dependiendo de cómo se vayan a colmar tales dudas, esto es, cómo se vaya a interpretar un determinado derecho (método), es que se podrá establecer la racionalidad argumentativa de una decisión judicial. 
Antes de entrar a esa evaluación, es necesario dejar por sentado que ante la señalada afirmación de que son los ciudadanos los que deben ejercer sus derechos en democracia, y como tal ser partícipes de la construcción de estos, propongo considerar las ideas de Robert Alexy (2010, pp. 79-81) como criterio orientativo del análisis que estamos efectuando. Este autor reflexiona identificando a los derechos fundamentales y la democracia deliberativa como exigencias cardinales del contenido y de la estructura de un sistema democrático en el cual la jurisdicción constitucional, si no quiere incurrir en una lógica de paternalismo incompatible con la idea de autodeterminación democrática, debe representar argumentativamente a las personas.

Alexy propone que debe plantearse qué es aquello que las personas racionales, con concepciones del bien distintas, consideran como condiciones de cooperación social justas tan importantes como para que un legislador no pueda decidir sobre ello (Alexy, 2003, p. 40). Ante esto se debe considerar una justicia constitucional que aspire a una representación de las personas con un discurso que sea coherente con lo que ellas piensan, como si pudieran formar parte del discurso jurídico constitucional racional y aprobasen también los argumentos expuestos en la sentencia dictada por el tribunal. Para que esto sea considerado así es necesario que un número suficiente y considerable de personas acepten estos argumentos como razones de corrección, y se requiera el empleo de argumentos correctos y razonables, y sobre todo, personas racionales que estén de acuerdo con los argumentos empleados por el tribunal, precisamente porque son razonables y correctos (Alexy, 2006, p.17). Además, el autor alemán añade que los tribunales se encuentran sometidos al escrutinio y crítica pública que se derivan de las exigencias de la responsabilidad que poseen en virtud al ordenamiento jurídico al que se deben.

En consecuencia, al ser incoherente la Sentencia 84 del 2017 con la decisión del pueblo boliviano sobre la reelección del presidente y vicepresidente del Estado, es posible inferir que esta sentencia no goza de la legitimidad necesaria, lo cual, de cierta manera, hace dudosa la racionalidad del proceso interpretativo-argumentativo que ha ejercido el Tribunal Constitucional al resolver el caso planteado, más aún cuando en ninguna parte de la sentencia se hace mínima cita y evaluación del referendo del 2016.

Asimismo, como la Corte Interamericana de Derechos Humanos ha establecido que el control de convencionalidad debe ser practicado 
y ejercido por todos los jueces y tribunales de un Estado ${ }^{3}$, es posible extender las ideas de Alexy a este tipo de control, sobre todo porque, en el caso particular que nos encontramos analizando, dicho control ha sido empleado por el TCP como un elemento central dentro de su argumentación y porque seguramente también lo harán los órganos del Sistema Interamericano de Protección de los Derechos Humanos.

\section{Hacia la aplicación de un control de convencionalidad con mayor legitimidad interpretativa y racional que el efectuado en la sentencia 84 del 2017}

Al extenderse el parámetro de legitimidad de Alexy del control efectuado por el TCP boliviano a un posible control de convencionalidad que efectúe el Sistema Interamericano de Derechos Humanos debe considerarse también en términos como los que propone Habermas ("Demócratas pide medidas cautelares a la CIDH para evitar que Evo se repostule", 2018; "Demócratas pide a CIDH resolver medida cautelar sobre reelección indefinida”, 2018). Este autor, en una posición contraria a la jurisprudencia de valores, se apoya en el pensamiento de Klaus Günther, quien ha expresado que una interpretación adecuada de las normas jurídicas a un caso concreto pretende "[...] justificar de tal suerte la primacía de esa norma como la única pertinente o adecuada, que no se viole el ideal de un sistema coherente de normas válidas[...]" (como se cita en Letelier, 2011, p. 383). Así, para Habermas, el problema de la aplicación de las normas debe orientarse a ser coherentes con el sistema al que pertenecen, pues los derechos considerados como principios deben ser tomados como normas obligatorias y no solo como valores sujetos a una discusión de preferencias, negándose así a la ponderación discrecional y arbitraria de los valores a aplicarse en un caso concreto. Este autor advierte además que esta concepción de aplicación de los derechos como valores tiene el peligro de que los jueces pueden hacer primar argumentos funcionalistas por sobre argumentos normativos (Letelier, 2011, p. 383).

Precisamente, la Sentencia 84 del 2017 intenta basar en parte su justificación en el tratadista alemán Otto Bachof, partidario de la jurisprudencia de valores que Habermas rechaza y critica, haciendo alusión a la existencia de normas constitucionales inconstitucionales planteada por Bachof, en la que normas constitucionales son contrarias

3 Véase la nota al pie 5. 
a otras de rango superior como los valores supremos, los principios fundamentales y los derechos y garantías que la Constitución pretende implantar. Esta afirmación fue así incluida en la sentencia pese a que en realidad dicho tratadista no está del todo de acuerdo con esta posición (Bachof, 2010, pp. 78-80). Sin embargo, la sola alusión a esta corriente de pensamiento jurídico permite aclarar la orientación que el TCP imprimió en su sentencia, con la cual particularmente no comulgamos.

Ahora bien, el TCP no solo se orientó con base en esa línea, pues paradójicamente encontramos también que aplicó en el fondo una lógica legalista cerrada, exegética, interpretando el derecho a ser elegido y sus limitaciones contenidas en el artículo 23 de la CADH como numerus clausus. De esta manera, esta entidad obvió una adecuada interpretación sistémica de la que nos habla Habermas y que también exige el artículo 31 de la Convención de Viena sobre el Derecho de los Tratados ${ }^{4}$, esto en virtud a que la propia Corte Interamericana de Derechos Humanos ha estimado que la interpretación gramatical "no puede ser una regla por sí misma, sino que debe involucrarse dentro del contexto -interpretación sistémica-y, en especial, dentro del objeto y fin del tratado" (Corte Interamericana de Derechos Humanos, 2001, 31 de agosto) ${ }^{5}$.

Pese a que la sentencia citó jurisprudencia de la Corte Interamericana de Derechos Humanos (siguiendo un método de interpretación conforme), con el supuesto de que “[...] los jueces y órganos vinculados a la administración de justicia deben tener en cuenta no solamente el Pacto de San José, sino también la interpretación que del mismo ha hecho la Corte Interamericana, intérprete última de la Convención Americana” (Corte Interamericana de Derechos Humanos, 2010, 26 de noviembre) ${ }^{6}$. Es notorio que tales precedentes judiciales no se adecúan, primero, en sus supuestos fácticos a la cuestión del derecho a ser elegido y su límite de prohibición de más de una reelección y, segundo, constituyen citas sesgadas. El caso Castañeda Gutman vs. México es un ejemplo notorio, en el

4 La Corte Interamericana de Derechos Humanos ha aplicado como estándares interpretativos los contenidos en el mencionado artículo 31: "[...] Para la interpretación del artículo 64 de la Convención la Corte utilizará los métodos tradicionales del Derecho Internacional, tanto en lo que se refiere a las reglas generales de interpretación, como en lo que toca a los medios complementarios, en los términos en que los mismos han sido recogidos por los artículos 31 y 32 de la Convención de Viena sobre el Derecho de los Tratados[...]”. (Corte Interamericana de Derechos Humanos, 1982, párr. 33).

5 Véase Corte Interamericana de Derechos Humanos (2006, 31 de enero; 2006, 1. ${ }^{\circ}$ de febrero).

6 Además, la propia SCP 0084 del 2017 hace alusión a su obligación de seguir las

interpretaciones de la Corte Interamericana de Derechos Humanos, en el marco de un control de convencionalidad. 
cual pese a que el Sr. Jorge Castañeda alegó (al igual que en el presente caso) que no pueden existir otras restricciones al ejercicio de sus derechos políticos fuera de los consagrados en el artículo 23.2 de la CADH (los llamados numerus clausus), la Corte Interamericana de Derechos Humanos, por su parte, resolvió que la negación a la inscripción de su candidatura a la presidencia no consistió en una violación a sus derechos políticos, en razón a que "no es posible aplicar al sistema electoral que se establezca en un Estado solamente las limitaciones del párrafo 2 del artículo 23 de la Convención” (Corte Interamericana de Derechos Humanos, Sentencia del 6 de agosto del 2008, párr. 145, 161). La razón es que

la Convención Americana no establece una modalidad específica o un sistema electoral particular mediante el cual los derechos a votar y ser elegido deben ser ejercidos [...]. La Convención se limita a establecer determinados estándares dentro de los cuales los Estados legítimamente pueden y deben regular los derechos políticos, siempre y cuando dicha reglamentación cumpla con los requisitos de legalidad, esté dirigida a cumplir con una finalidad legítima, sea necesaria y proporcional; esto es, sea razonable de acuerdo a los principios de la democracia representativa (Corte Interamericana de Derechos Humanos, Sentencia del 6 de agosto del 2008, párr. 149).

De esta forma, la Corte Interamericana de Derechos Humanos también justificó la restricción a los derechos políticos en virtud al art. 32.2. de la CADH, el cual establece que "Los derechos de cada persona están limitados por los derechos de los demás, por la seguridad de todos y por las justas exigencias del bien común en una sociedad democrática” (Corte Interamericana de Derechos Humanos, Sentencia del 6 de agosto de 2008, párr. 175-205).

Precisamente, siguiendo una interpretación sistémica, la Comisión Interamericana de Derechos Humanos, en el caso Ríos Montt vs. Guatemala, también decidió fundar su posición en el referido artículo 32. 2 de la CADH (Comisión Interamericana de Derechos Humanos, Informe 30 de 1993, párr. 22). También aplicó la doctrina del margen de apreciación nacional ${ }^{7}$ para discernir sobre la licitud (inconvencionalidad) de la restricción establecida por el artículo 186 de la Constitución de

7 Esta apreciación por cierto es escasa o casi inexistente en el Sistema Interamericano. 
Guatemala que prohíbe a ex jefes de un golpe de Estado la elección al cargo de presidente. En ese tracto, además de observar la existencia de un tratado suscrito entre Nicaragua y otros países centroamericanos que establece la inelegibilidad, ha estimado que esta no constituye un factor de discriminación, por cuanto, de manera comparativa, existen en la región sistemas que prohíben la reelección de autoridades elegidas democráticamente. De esta manera, afirmó la Comisión, que considerar al artículo 186 de la Constitución de Guatemala inconsistente con el artículo 23 de la CADH pondría en situación de privilegio a quienes rompen el orden constitucional con respecto a quienes acceden constitucional y democráticamente a cargos electos (Comisión Interamericana de Derechos Humanos, Informe 30 de 1993, párr. 27-34).

Pese a que no se refiere exclusivamente a la cuestión de la reelección, lo destacable de este precedente es que la Comisión emplea el margen de apreciación nacional para aceptar que los sistemas constitucionales declaren límites a la elección y reelección a cargos públicos, lo que da cabida a que el artículo 32. 2 sea una norma sistémica interpretativa (Comisión Interamericana de Derechos Humanos, Informe 30 de 1993, párr. 22-26).

Es necesario profundizar en los alcances del artículo 32.2 de la CADH con el fin de establecer si el límite de una sola reelección presidencial es convencional o inconvencional, en virtud a que, en palabras de la Corte Interamericana de Derechos Humanos, este artículo es un criterio de interpretación que tiene por utilidad armonizar los derechos y sus correspondientes limitaciones (Corte Interamericana de Derechos Humanos, La colegiación obligatoria de periodistas, párr. 41). Sin embargo, el primer aspecto con el que tropezamos es que “[...] para una aplicación unívoca de las cláusulas limitativas lo encontramos en que ellas están pobladas de conceptos indeterminados" (Thompson, como se cita por Pinto, 1997, p. 168), es decir, son términos vagos que llevan a zonas de penumbra como "bien común” o "justas exigencias en una sociedad democrática".

Pese a esto, la Corte Interamericana de Derechos Humanos ha establecido que es posible justificar restricciones o limitaciones al ejercicio de ciertos derechos para asegurar el orden público; en otras palabras, señaló que “[...] es válido sostener, en general, que el ejercicio de los derechos garantizados por la Convención debe armonizarse con el bien común” (Corte Interamericana de Derechos Humanos, La colegiación obligatoria de periodistas, párr. 65). Así para la Corte, el bien común consistiría 
en un "[...] concepto referente a las condiciones de la vida social que permiten a los integrantes de la sociedad alcanzar el mayor grado de desarrollo personal y la mayor exigencia de los valores democráticos" (Corte Interamericana de Derechos Humanos, La colegiación obligatoria de periodistas., párr. 66). No obstante, expresa tajantemente que ni la invocación al orden público ni al bien común podrán suprimir un derecho garantizado por la Convención, en virtud al artículo 29. a de este cuerpo normativo. Precisamente esta última disposición se cita en la Sentencia 84 del 2017 para aducir que

\section{[...] El art. 23 de la CADH, consigna derechos políticos de la manera más amplia, sin ningún tipo de limitaciones o restricciones, autorizando únicamente al legislador la regulación de su ejercicio por causales taxativas en la forma anteriormente señalada; sin que ninguna de ellas en particular, tenga que ver en lo absoluto, con eventuales restricciones a la posibilidad de ser reelecta o reelecto y menos que ésta se limite a una sola vez de manera continua [...] (art. 2).}

Como dijimos anteriormente, esta sentencia constitucional ha empleado sesgadamente la jurisprudencia interamericana, y por tanto, ha aplicado incorrectamente el criterio de interpretación conforme, debido a que, si bien la Corte ha reafirmado el citado artículo 29. a) de la CADH, los conceptos de orden público o el bien común

\footnotetext{
[...] en cuanto se invoquen como fundamento de limitaciones a los derechos humanos, deben ser objeto de una interpretación estrictamente ceñidas a las ‘justas exigencias' de 'una sociedad democrática' que tenga en cuenta el equilibrio entre los distintos intereses en juego y la necesidad de preservar el objeto y fin de la Convención (Corte Interamericana de Derechos Humanos, OC-5/85, párr. 67).
}

Por lo tanto, es racional que se impongan límites al derecho de ser elegido democráticamente, ya que perfectamente es posible considerar que es "[...] un imperativo del bien común la organización de la vida social en forma que se fortalezca el funcionamiento de las instituciones democráticas y se preserve y promueva la plena realización de los derechos de la persona [...]" (Corte Interamericana de Derechos Humanos, OC-5/85, párr. 66). 


\section{Una interpretación de la Corte Interamericana de Derechos \\ Humanos que permite compatibilizar el control de convencionalidad con la decisión popular del referendo del 2016}

En la misma lógica sistémica de interpretación de los límites al supuesto derecho de reelección de autoridades, encontramos en el artículo 30 un complemento al explorado artículo 32.2 de la CADH. Como veremos la interpretación al artículo 30 efectuada por la Corte Interamericana de Derechos Humanos permite compatibilizar el Pacto de San José con la voluntad popular del referendo de 2016. De esta forma, aquella norma convencional dispone: "Las restricciones permitidas, de acuerdo con esta Convención, al goce y ejercicio de los derechos y libertades reconocidas en la misma, no pueden ser aplicadas sino conforme a leyes que se dictaren por razones de interés general y con el propósito para el cual han sido establecidas". Se hace, no obstante, nuevamente notorio un problema de ambigüedad y vaguedad que dificulta una adecuada interpretación de la norma, lo cual llevó a que Uruguay solicite una Opinión Consultiva a la Corte con el fin de aclarar la expresión leyes, contenida en la mencionada disposición.

En su determinación, la Corte Interamericana de Derechos Humanos observó que el término leyes "[...] no puede tener otro sentido que el de la ley formal, es decir, norma jurídica adoptada por el órgano legislativo y promulgada por el Poder Ejecutivo, según el procedimiento requerido por el derecho interno de cada Estado" (Corte Interamericana de Derechos Humanos, OC-6/86, párr. 27). Le otorga así al principio de legalidad un papel importante, pero no suficiente, por cuanto

\footnotetext{
[...] la Convención no se limita a exigir una ley para que las restricciones al goce y ejercicio de los derechos y libertades sean jurídicamente lícitas. Requiere, además, que esas leyes se dicten 'por razones de interés general y con el propósito para el cual han sido establecidas' (Corte Interamericana de Derechos Humanos, OC-6/86, párr. 28).
}

La Corte afirma que significa que las restricciones a los derechos deben haber sido adoptadas en función del bien común, el cual es un concepto que ha de interpretarse como un elemento integrante del orden público del Estado democrático. El significado que la Corte le otorgó a ambos términos los volvió a plantear conforme a la definición descrita en el apartado anterior (Corte Interamericana de Derechos Humanos, OC-6/86, párr. 31). 
En consecuencia, para la Corte Interamericana de Derechos Humanos, el término leyes se refiere a los

[...] actos normativos enderezados al bien común, emanados del Poder Legislativo democráticamente elegido y promulgados por el Poder Ejecutivo [...]. Solo la ley formal, entendida como lo ha hecho la Corte, tiene aptitud para restringir el goce o ejercicio de los derechos reconocidos por la Convención. (Corte Interamericana de Derechos Humanos, OC-6/86, párr. 35)

Se establece asimismo la posibilidad de que existan delegaciones legislativas en esta materia

[...] siempre que tales delegaciones estén autorizadas por la propia Constitución, que se ejerzan dentro de los límites impuestos por ella y por la ley delegante, y que el ejercicio de la potestad delegada esté sujeto a controles eficaces, de manera que no desvirtúe, ni pueda utilizarse para desvirtuar, el carácter fundamental de los derechos y libertades protegidos por la Convención (Corte Interamericana de Derechos Humanos, OC-6/86, párrs. 35-36).

En definitiva, extrapolando esta interpretación al caso del derecho a ser elegido democráticamente y al límite de una sola reelección, es perfectamente posible que la Constitución de Bolivia imponga esta restricción y que esta no sea considerada contraria a la Convención Americana. De la misma manera, se debe extender la misma consideración a la Ley del Régimen Electoral que la regula, todo por la lógica de delegaciones autorizadas por la Constitución, de las que precisamente nos habla la Corte Interamericana de Derechos Humanos.

Así, cuando concurren todos estos elementos que configuran el concepto de ley expresado en el artículo 30 de la CADH, según la Corte es posible concluir que

\section{[...] los conceptos de legalidad y legitimidad coinciden a los efectos} de la interpretación de esta norma, ya que solo la ley adoptada por los órganos democráticamente elegidos y constitucionalmente facultados, ceñida al bien común, puede restringir el goce y ejercicio de los derechos y libertades de la persona humana (Corte Interamericana de Derechos Humanos, OC-6/86, párr. 37). 
Mutatis mutandis, respecto a la configuración del derecho a ser elegido y del límite de una sola reelección, bien podríamos postular la presencia de una lógica de deferencia ${ }^{8}$ por parte de la Corte Interamericana de Derechos Humanos hacia lo que el constituyente y el legislador han definido. Esto porque, en términos similares, se podría configurar la propuesta que Moreso ha planteado en su diálogo controversial con Bayón, quien sugiere que sobre la base de distinguir entre casos claros y casos difíciles: "[...] la deferencia del órgano jurisdiccional de control de la constitucionalidad debe ir en relación inversa a la claridad del caso enjuiciado" (Moreso, 2009, p. 144).

Así, en ese marco, una adecuada aplicación del control de convencionalidad y de constitucionalidad por parte del TCP debía consistir en una adecuada aplicación del principio de interpretación conforme, que incluyera los artículos 30 y 32.2 de la CADH y la jurisprudencia que los interpreta. Por tanto, se debía dar una deferencia hacia lo ya regulado por el Constituyente y delegado hacia el legislador respecto al establecimiento legal y legítimo del límite de una sola reelección para las autoridades nacionales y subnacionales. Por tanto, debido a que el mencionado límite no es inconvencional o contrario a la $\mathrm{CADH}$, es posible concluir que este instrumento no es más favorable para las personas que los derechos políticos contenidos en la Constitución de Bolivia, lo cual, también lógicamente deriva en una incorrecta aplicación del principio pro homine.

\section{Conclusión}

Primero, se ha observado que en Bolivia cuando menos tres niveles de autoridad reclaman normativamente el poder de definir el derecho a ser elegido y sus límites: el pueblo, el Tribunal Constitucional y los tribunales supranacionales, tales como la Corte Interamericana de Derechos Humanos.

Segundo, al producirse un resultado recíprocamente contrario entre la Sentencia 84 del 2017 y el referendo del 21 de febrero del 2016, se observó que la propuesta de Alexy proporciona un sugerente parámetro sobre la legitimidad de la decisión constitucional, la cual muestra la necesidad de que el razonamiento judicial deba ser, en cierta forma,

8 También se puede entender como la aplicación de la doctrina del margen de apreciación nacional. 
compartido por un gran número de ciudadanos (por no decir por la mayoría) dentro de una comunidad política, el cual debe contener razones aceptadas por estos, como si ellos mismos fueran parte del proceso deliberativo judicial.

Tercero, el TCP aplicó el control de convencionalidad para declarar la inaplicabilidad de las normas constitucionales y legales que establecen una sola reelección de autoridades; al hacerlo ha usado defectuosamente el principio de interpretación conforme (art. 13.IV de la CPE), pues no desarrolla una interpretación sistémica amplia que permitiera considerar en toda su magnitud algunos casos que ha citado en su argumentación y obvió algunas normas de la propia CADH (como los artículos 30 y 32.2) y las interpretaciones que la Corte Interamericana de Derechos Humanos ha desarrollado sobre estas. Estas últimas permiten observar que no se puede interpretar como numerus clausus a los límites señalados en el numeral 2 del artículo 23 de la CADH.

Por último, el artículo 30 y su interpretación desarrollada por la Corte Interamericana de Derechos Humanos ayuda a que la Constitución y leyes impongan límites a los derechos en función al bien común e interés general de la sociedad, lo que hace vislumbrar una actitud de deferencia hacia el constituyente y legislador. De esta forma, al enmarcarse en esta disposición el límite de una sola reelección de las autoridades bolivianas, se colige su convencionalidad, y esto provoca la invalidación de la interpretación del TCP que supone la mayor favorabilidad del artículo 23 de la CADH respecto a la Constitución de Bolivia en relación al derecho político a ser elegido democráticamente.. Además, se pudo demostrar que la paradoja entre voluntad popular y control de convencionalidad (legitimidad democrática frente a la legalidad convencional) no es más que una artificial apariencia provocada por la sentencia del TCP.

\section{Referencias}

Alexy, R. (2003). Los derechos fundamentales en el estado constitucional democrático. En Miguel Carbonell (Ed.), Neoconstitucionalismos(s) (pp. 31-48). Madrid: Trotta.

Alexy, R. (2006). Ponderación, control de constitucionalidad y representación. En Perfecto Andrés Ibañez y Roberta Álexy (Ed.), Jueces y ponderación argumentativa (pp. 1-18). Ciudad de México: unAm.

Alexy, R. (2010). Los principales elementos de mi filosofía del derecho. Doxa, 2010(32), 79-81. 
Bachof, O. (2010). ¿ ¿Normas constitucionales inconstitucionales? Lima: Palestra.

Corte Interamericana de Derechos Humanos. (1982, 24 de septiembre). Opinión Consultiva OC-1/82 tratados objeto de la función consultiva de la Corte. Recuperado de http://www.acnur.org/index.php?id=872\&L=0\&tx_news_ pi1\%5Bnews\%5D=13429\&tx_news_pi1\%5Bcontroller\%5D=News\&tx_news_ pi1\%5Baction\%5D=detail\&cHash=090b8271c6d1f632af66309cbdee127d

Corte Interamericana de Derechos Humanos (2001, 31 de agosto). Caso de la Comunidad Mayagna (Sumo) Awas Tingni.

Corte Interamericana de Derechos Humanos (2006, 31 de enero). Votos Razonados en los Casos de la Masacre de Pueblo Bello.

Corte Interamericana de Derechos Humanos (2006, 1. . de febrero). Caso López Álvarez.

Corte Interamericana de Derechos Humanos. (2010, 26 de noviembre). Caso Cabrera García y Montiel Flores vs. México. Excepciones preliminares, fondo, reparaciones y costas.

Demócratas piden medidas cautelares a la CIDH para evitar que Evo se repostule. (2018, 19 de febrero). El Deber. Recuperado de https://www. eldeber.com.bo/bolivia/Presentan-accion-ante-la-CIDH-para-defender-el21-F-20180219-0088.html

Demócratas piden a CIDH resolver medida cautelar sobre reelección indefinida. (2018, 26 de febrero). Los Tiempos. Recuperado de http://www.lostiempos. com/actualidad/pais/20180226/democratas-pide-cidh-resolver-medidacautelar-reeleccion-indefinida

Letelier, R. (2011). La justicia constitucional en el pensamiento de Jürgen Habermas. Revista Estudios Constitucionales, 9(2), 377-394.

Recuperado de https://scielo.conicyt.cl/scielo.php?script=sci_ arttext\&pid=S0718-52002011000200009

Ferrajoli, L. (2013). Principia Iuris, tomo II. Madrid: Trotta.

Gil, A. (2014). Derechos, racionalidad y última palabra. Buenos Aires: Ediar.

Moreso, J. J. (2009). La constitución: modelo para armar. Madrid: Marcial Pons.

Órgano Electoral Plurinacional de Bolivia. (2011). Elección de autoridades del Órgano Judicial y del Tribunal Constitucional. Resultados finales. Recuperado de https://www.oep.org.bo/wpcontent/uploads/2017/03/separata_resultados_ judiciales_2011.pdf

Pinto, M. (1997). El principio pro homine. Criterios de hermenéutica y pautas para la regulación de los derechos humanos. En Abrahamovich, V. Abregú, M., \& Courtis, Christian (eds.), La aplicación de los tratados sobre derechos humanos por los tribunales locales (pp. 163-171). Buenos Aires: Editores del Puerto.

TCP. (2017). SCP 0084. Recuperado de https://buscador.tcpbolivia.bo/servicios/ (S(5jjf5wjsej45iqvloe040nll))/WfrMostrarResolucion.aspx?b=150754

Waldron, J. (2005). Derecho y desacuerdo. Madrid: Marcial Pons. 